\begin{tabular}{|c|l|}
\hline Title & Critical reflection, unlearning, and engagement \\
\hline Author(s) & Matsuo, Makoto \\
\hline Citation & $\begin{array}{l}\text { Management learning, 50(14), UNSP 1350507619859681 } \\
\text { https://doi.org/L0.1177/1350507619859681 }\end{array}$ \\
\hline Issue Date & 2019-07-09 \\
\hline Doc URL & http://hdl.handle.net/2115/80391 \\
\hline Type & article (author version) \\
\hline File Information & Self-archiving (ML 2019)rv.pdf \\
\hline
\end{tabular}

Instructions for use 


\title{
Critical reflection, unlearning, and engagement
}

\author{
Makoto Matsuo \\ Hokkaido University, Japan \\ Email: mmatsuo@econ.hokudai.ac.jp
}

\begin{abstract}
Although individual unlearning is believed to play a critical role in promoting higherorder learning, there has been little quantitative research on this process. This article aimed to investigate the antecedents and consequences of individual unlearning based on transformative learning theory. A survey was conducted among 301 employees working in various occupations and organizations in the United States. The results of structural equation modeling indicated that unlearning mediated the relationship between critical reflection and work engagement and that critical reflection mediated reflection and unlearning. This study contributes to the literature by quantitatively demonstrating the direct and indirect influences of critical reflection on work engagement through individual unlearning, which has been discussed only conceptually and qualitatively in the extant transformative learning literature.
\end{abstract}

\section{Keywords}

Critical reflection, reflection, unlearning, work engagement

\section{Introduction}

Unlearning, or abandoning obsolete beliefs, values, knowledge, and routines (Akgün et al., 2006; Becker, 2005; Hislop et al., 2014; Tsang and Zhara, 2008), is important for the growth of both organizations and individuals, because existing knowledge or habits are often barriers to new learning (Becker, 2005). To survive in turbulent environments, employees must replace or update obsolete ways of working with new ones. Unlearning is thus a significant step for generative learning and exploration (Fernandez et al., 2012).

However, individuals tend to maintain the status quo and prefer to continue following existing routines to which they have become accustomed (Tsang, 2008). That is, 
individuals tend to engage in exploitive activities, focusing on what they already know, rather than on exploratory activities or to search for new ways of approaching a task (March, 1991). Therefore, it is important to understand how individuals abandon their beliefs or work routines. Although unlearning is believed to play a significant role in higher-order learning, such as transformative learning (Metzirow, 1990, 1991, 2000) and double-loop learning (Argyris, 1976), prior studies have neglected the process at the individual level (Hislop et al., 2014). Furthermore, little quantitative research has been carried out on the antecedents and consequences of individual unlearning. Notably, the existing literature has emphasized the role of critical reflection in higher-order learning (Cope, 2003; Cunliffe, 2004, 2016; Metzirow, 1990, 1991, 2000; Reynolds, 1998), whereas the relationship has not been sufficiently investigated with survey data.

To fill the research gap, this study, which was based on transformative learning theory (Metzirow, 1990, 1991, 2000), quantitatively investigated the effects of reflection, which focuses on problem solving, as well as critical reflection, which reassesses our taken-forgranted assumptions (Cope, 2003; Gray, 2007; Raelin, 2001; Reynolds, 1998) on individual unlearning. Specifically, assuming that reflection can form a basis or foundation for critical reflection, the present research tested the hypothesis that reflection leads to critical reflection, which results in unlearning.

Regarding the consequences of unlearning, this research focused on work engagement, defined as a positive, fulfilling, work-related state of mind characterized by vigor, dedication, and absorption (Schaufeli et al., 2002). There are two reasons for including work engagement in the research model. First, work engagement has been shown to be a critical predictor of positive outcomes, including organizational commitment, productivity, citizenship behavior, innovative work behaviors, and performance (Bakker and Albrecht, 2018; Christian et al., 2011; De Clercq et al., 2014; Van De Voorde et al., 2016). Second, prior research has found that work engagement is promoted by job crafting, defined as proactively changing one's job demands and resources (Bakker et al., 2012; Tims and Bakker, 2010), which is conceptually associated with unlearning in terms of changing work practices. The proposed research model postulates that critical reflection has direct and indirect positive influences on work engagement through individual unlearning.

The research presented in this paper makes two main contributions to the existing literature. First, the findings confirm the previously insufficiently proven relationship between critical reflection and unlearning. Although critical reflection is generally believed to have played a key role in promoting transformative learning (Metzirow, 1991) and double-loop learning (Argyris, 1976), the effects of critical reflection on unlearning 
have not been quantitatively confirmed. Additionally, Pfeffer and Sutton's (1999) "knowing-doing gap" underscores that knowledge is not always put to use (i.e., the relationship between critical reflection and unlearning is not self-evident). This study contributes to the existing literature by confirming the positive influence of critical reflection on unlearning, which had not been quantitatively examined in past research.

Second, this study extends the research on the employee engagement process by clarifying the role of critical reflection, which directly and indirectly enhances work engagement, mediated through unlearning. On the other hand, previous studies have demonstrated that a reflective approach to changing work practices and unlearning can cause anxiety, stress, and frustration (Cotter and Cullen, 2012; Cunliffe and Jun. 2005; Visser, 2017); therefore, rigorous empirical testing is needed to confirm such a positive relationship. The findings elucidate the mechanisms by which critical reflection promotes employee engagement, which have not been investigated in previous studies.

This paper is structured in the following way. First, the literature review on unlearning, reflection, critical reflection, and work engagement is conducted to develop hypotheses. Then, the methodology and results are described. Finally, the results are theoretically and practically discussed.

\section{Theoretical background}

\section{Individual unlearning}

In this research undertaking, individual unlearning was defined as the process by which individuals consciously choose to give up, abandon, or stop using outdated knowledge, values, or behaviors (Becker, 2005; Hislop et al., 2014; Tsang and Zhara, 2008). There are three implicit assumptions in this definition. First, unlearning at the individual level is a conscious or intentional process of abandoning knowledge, values, or behaviors (Hislop et al., 2014; Tsang and Zahra, 2008). Second, unlearned knowledge is not permanently forgotten, because it can still be referenced if necessary (Hislop et al., 2014). Third, discarding existing knowledge can, but may not, occur while simultaneously obtaining new knowledge (Becker, 2005; Cegarra-Navarro and Sánchez-Polo, 2011).

It is important to note that unlearning is not synonymous with learning; it is a step in the learning process. Three types of learning have been identified. The first is 'accumulative learning,' in which an individual obtains knowledge and skills without abandoning old ones. This approach corresponds to exploitation activities, in which individuals improve and extend their existing knowledge (March, 1991; Mom et al., 2007). The second type is 'updating or replacing learning,' in which individuals absorb new and discard old knowledge. The third is 'focusing or selective learning,' in which, 
for various reasons, individuals relinquish the use of some of the obsolete or outdated knowledge in their repertoire without acquiring new knowledge. Of these three types of learning, "unlearning" appears only in the second and the third, but it is not included in the first, accumulative learning. Thus, learning does not always involve unlearning.

In terms of the types of unlearning, Hislop et al. (2014) distinguished "deep unlearning" from "wiping", based on Rushmer and Davies (2004). Wiping, which can be defined as a superficial type of unlearning, refers to a deliberate process of change focusing on a relatively narrow practice or activity, whereas deep unlearning involves examining values and assumptions rather than particular behaviors or practices (Hislop et al., 2014).

Deep unlearning is associated with higher-order learning, such as transformative learning and double-loop learning (Hislop et al., 2014). Transformative learning refers to transforming a problematic frame of reference (or sets of fixed assumptions and expectations) to make it more dependable in adult life by forming opinions and interpretations that are more justified (Mezirow, 2000, 2003). Likewise, Argyris (2003) stated that double-loop learning occurs when individuals detect a mismatch and correct it by changing the underlying values and status quo that governs behavior. These definitions suggest that both transformative learning and double-loop learning involve the 'updating or replacing' type of learning at a deep level.

To operationalize unlearning, the present research used the measurement scale created by Akgün et al. (2006). In their research, unlearning was conceptualized as 'changes in beliefs and routines'. This scale has the advantage of appropriately measuring unlearning because beliefs and routines in business or work processes change when higher-order learning occurs. The development of the scale of individual unlearning involved the revision of items used in the scale created by Akgün et al. (2006) to render them applicable to various jobs at the individual level. In the present research, 'routines' refer to on-thejob behavioral patterns, such as the procedures or methods used to perform tasks. Prior studies have demonstrated that individuals' routines and beliefs strongly affect their attitudes and behaviors (Ajzen, 1985; Montano and Kasprzyk, 2015; Osgood et al., 1996) toward the relative contributions of teams' routines and beliefs. Thus, Akgün et al.'s (2006) scale, which was developed for team unlearning, may also be applicable to measuring individual unlearning. Considering the nature of routines and beliefs that guide individual behaviors, the unlearning measured in this study may be a deep unlearning rather than wiping.

However, Akgün et al.'s (2006) scale, which characterizes unlearning only as changes in beliefs and routines, encounters difficulties with regard to the transformative concept 
of unlearning, because a change does not necessarily involve abandoning old knowledge. Individuals can undoubtedly change our beliefs or routines by adding new knowledge without discarding old knowledge. Thus, the present research notably measured unlearning as changes in beliefs and routines that involve only abandoning obsolete, outdated beliefs and routines. As Akgün et al.'s (2006) scale was designed to assess all aspects of learning, this research selectively focused on measurements of 'updating or replacing' and 'focusing or selective learning', which may include abandoning beliefs and routines.

To a certain extent, individuals who are engaged in unlearning do not refuse to use all of their existing beliefs and routines. On the one hand, prior research suggests that individuals give up, abandon, or stop using beliefs and routines when they are deemed to be obsolete and outdated (Becker, 2005; Hislop et al., 2014; Tsang and Zhara, 2008). On the other hand, an individual may continue to use beliefs and routines that still function well in helping them to do their job. To recognize whether certain beliefs and routines are functional, individuals need to assess the effectiveness of their work practices and processes. Previous research suggests that unlearning is often triggered by an external change or crisis (Akgün et al., 2006; Hislop et al., 2014; Tsang and Zhara, 2008), which may induce individuals to reassess their beliefs and routines. In this sense, unlearning does not always occur voluntarily, but situational factors may often stimulate individuals to discard their obsolete beliefs and routines.

\section{Reflection and critical reflection}

Models of higher-order learning emphasize a critical assessment of an individual's frame of reference or mental model (Cope, 2003). However, behavioral change after particular events may take time, and individuals are required to question themselves with respect to their values and assumptions (Hislop et al., 2014). For example, Mezirow proposed a model of transformative learning with the following 10 steps: 1) a disorienting dilemma, 2) a self-examination with feelings of guilt or shame, 3) a critical assessment of assumptions, 4) a recognition of shared discontent, 5) an exploration of new roles, 6) the development of a course of action, 7) the acquisition of knowledge/skills to implement one's plan, 8) a provisional trial of new roles, 9) the development of competence/confidence, and 10) a reintegration into life (Brock, 2012; Mezirow, 2000). This model, which has been widely used in adult learning and higher education (Durant et al., 2017), suggests that multiple reflective steps are necessary to change an individual's beliefs and knowledge.

According to the renowned higher-order learning theory, and as per Kurman (2006), 
there are "recognition" and "action" stages of the self-improvement process. Selfregulated learning theory (Zimmerman, 2002) also distinguishes between "self-reflection" and "performance" phases. By incorporating multiple models, "recognition" may be interpreted as "reflection", and "action" may be referred to as "unlearning". Hence, unlearning (i.e., abandoning beliefs and routines) can be conceptualized as the action stage or performance phase of higher-order learning. To understand the higher-order learning process as a whole, it is necessary to examine the links between the recognition and action stages.

Regarding the recognition stage of learning, prior studies have argued that reflection, or the practice of 'periodically stepping back to consider the meaning of what has recently happened in our environment' (Raelin 2002), is key to self-insight (Stein and Grant, 2014), learning and positive work outcomes (Boud et al., 2006; Gallagher et al., 2007). Kolb's (1984) experiential learning theory also postulates that reflective observation is necessary for learning from experience. These theories suggest that individuals need to reflect on their experiences to unlearn beliefs or routines.

Importantly, it is necessary to distinguish 'reflection' from critical reflection. Specifically, reflection mainly focuses on the immediate details of tasks or problems, while critical reflection refers to examining our taken-for-granted beliefs and assumptions to be receptive to alternative ways of thinking and different behaviors (Gray, 2007; Raelin, 2001; Reynolds, 1998). Critical reflection, which involves critiquing and raising questions regarding the validity of those presuppositions, is related to 'problem posing' rather than 'problem solving' (Mezirow, 1991).

These arguments indicate that critical reflection functions as a higher level of reflective activity than simple reflection, as the former promotes the transformation of an individual's meaning framework (Kember et al., 2000). Cunliffe (2004) distinguished between the two concepts by using Argyris' (1976) notions of single-loop and doubleloop learning. Specifically, reflection is associated with single-loop learning, which emphasizes problem solving and correcting errors, whereas critical reflection is required for double-loop learning, which involves questioning existing values and assumptions to evaluate new ones in terms of their performance (Cunliffe, 2004). Mezirow $(1990,1997)$ suggested that critical reflection can facilitate transformative learning, or the process of changing the structures of assumptions or a frame of reference through which individuals understand their experiences. Based on this context, individuals who critically reflect on their values and assumptions tend to be aware of obsolete beliefs and routines that should be discarded. Thus, it is presumed that critical reflection positively influences unlearning.

On the other hand, reflection may have no direct impact on unlearning, because it 
focuses on the immediate details of tasks or problems (Gray, 2007; Raelin, 2001; Reynolds, 1998). However, it is also possible that reflection promotes critical reflection, because individuals who frequently reflect on their tasks or problems have more chances to identify the inappropriateness of their values or assumptions. Even when it is not critical, reflection has been shown to promote innovative work behaviors, such as promotion and realization of ideas (Messmann and Mulder, 2015). Considering the difficulties associated with being engaged in critical reflection (van Woerkom, 2010), frequent reflection on work processes or objectives may serve as a fundamental basis for critical reflection on values or assumptions. As described earlier, Mezirow's (2000) transformative learning model includes the stage of 'self-examination with feelings of guilt or shame' before 'critical assessment on assumptions.' Given these considerations, the following mediation hypothesis was suggested:

H1. Critical reflection partially mediates the relationship between reflection and unlearning.

\section{Work engagement}

This study is focused on work engagement as a consequence of unlearning for two reasons. First, work engagement, as a positive, work-related state of mind, has been shown to be a very good predictor of important employee outcomes, such as job satisfaction, organizational commitment, citizenship behaviors, innovative work behaviors, and job performance (Agarwal, 2014; Bakker and Albrecht, 2018; Garrick et al., 2014; Lu et al., 2014; Reis et al., 2016; Schaufeli et al., 2006; Shantz et al., 2016). Work engagement is conceptualized as the positive antipode of burnout (Schaufeli et al., 2006), whereas it constitutes a mode of intrinsic motivation whereby an activity is performed for itself to experience engagement and pleasure (Demerouti et al., 2015; Reis et al., 2016). Thus, individuals who commit to changing their beliefs and routines are likely to have a positive psychological state of mind at work.

Second, prior research found that work engagement is enhanced by job crafting, or a self-initiated change to align one's responsibilities with one's preferences, motives, and passions, on work engagement (Tims et al., 2012; Bakker et al., 2012). According to Tims et al. (2012), job crafting consists of four dimensions: increasing social job resources (e.g., asking for feedback), increasing structural job resources (e.g., developing capabilities), increasing challenging job demands (e.g., taking on extra tasks), and decreasing hindering job demands (e.g., avoiding emotionally intense work). Except for decreasing hindering job demands, the other three dimensions were reported to facilitate work engagement (Bakker et al., 2012; Demerouti et al., 2015). 
Regarding the relationship between job crafting and work engagement, Bakker et al. (2012) suggested that employees who mobilize their job resources and create a challenging work environment are likely to feel enthusiasm for and be absorbed by their jobs. Although the concept of job crafting does not necessarily involve questioning assumptions or beliefs, such concepts may have characteristics in common with unlearning, because both are related to changing elements of work. Thus, it is assumed that unlearning, which entails changing beliefs and routines through abandoning obsolete knowledge, may promote work engagement by enhancing intrinsic motivation. Based on Hypothesis 1 and the foregoing arguments, the following mediation hypothesis was proposed:

H2. Unlearning partially mediates the relationship between critical reflection and work engagement.

Drawing on Dewey's (1933) arguments, Carson and Fisher (2006) stated that reflective individuals possess certain characteristics, such as a willingness to accept intellectual responsibility, a willingness to face uncertainties, and enthusiasm. Previous psychological research also reported that self-reflection is positively related to cognitive flexibility (Sauter et al., 2010) and negatively related to depression (Simsek, 2013). Furthermore, Stein and Grant (2014) found that self-reflection and insight positively influence subjective well-being, which is mediated via core self-evaluations or a basic appraisal of one's worthiness, effectiveness, and capability. These findings suggest that self-reflection promotes individuals' well-being by enhancing their cognitive capabilities and evaluation of their effectiveness. As work engagement is characterized by vigor, dedication, and absorption (Schaufeli et al., 2002), reflection may enhance work engagement by inducing individuals to positively assess their capabilities.

It should be noted, however, that reflection may have a weaker influence on work engagement, as reflection focuses primarily on solving problems rather than on posing problems (Gray, 2007; Raelin, 2001; Reynolds, 1998). That is, 'problem posing' may be promoted by the 'problem-solving' activities that occur during general reflection. Therefore, reflection may provide a foundation for critical reflection. Based on the foregoing arguments, it is assumed that reflection indirectly influences work engagement mediated through critical reflection. Based on Hypothesis 1, the following mediation hypothesis was suggested:

H3. Critical reflection partially mediates the relationship between reflection and work engagement.

Figure 1 shows the research model used in this study, which consists of the three mediation hypotheses discussed above. 


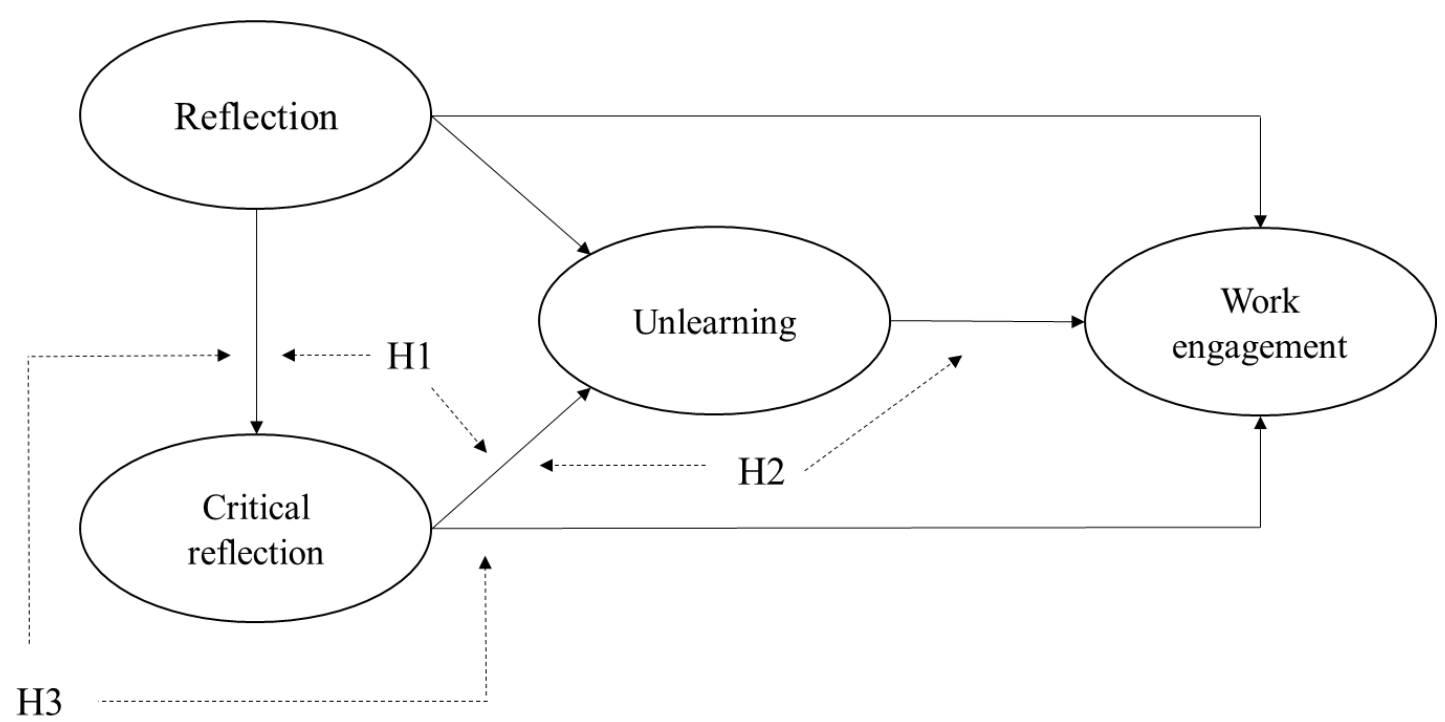

Figure 1. Research model.

\section{Method}

\section{Participants and procedure}

An online survey to collect data was conducted by a research company. Subjects were employees at various organizations in the US who were registered in research pools managed by this firm. Potential respondents in the pools were invited to participate in the online survey. They were informed that participation in the survey was anonymous and voluntary before they completed the questionnaires. Among the 867 questionnaires delivered, 622 usable questionnaires were returned. As this study focused on full-time employees with more than 5 years of work experience, responses from part-time, temporary, unemployed, and self-employed workers, and employees with less than 5 years of work experience, were excluded. This is because the research model, including unlearning and work engagement, had to be tested using data collected from employees with a certain amount of work experience in responsible positions. Specifically, unlearning requires that employees have established work-related beliefs and routines, which are acquired through productive work experiences and seniority. Full-time employees with a minimum of 5 years of experience should be considered appropriate targets for unlearning approaches. On the other hand, less experienced and part-time employees may not need to unlearn at an extent as full time and experienced do. As a result of this selection, 301 responses were considered in the analysis (final response rate was $34.7 \%$ ).

This online survey-based procedure has an advantage with respect to the collection of data from employees who work for various kinds of organizations (Holland et al., 2013) 
in different geographical locations (Ahn et al., 2007). Previous studies in which similar online surveys were adopted reported that the measurement had sufficient discriminant and convergent validity as well as high reliability (e.g., Ahn et al., 2007; Jiang, 2016; Parry et al., 2012).

The sample included 153 males (50.8\%) and 148 females (49.2\%). Regarding age, $18.6 \%$ were $25-29$ years old, $54.9 \%$ were $30-39$ years old, $24.9 \%$ were $40-49$ years old, and $1.7 \%$ were $50-54$ years old. The mean organizational tenure was 6.50 years $(\mathrm{SD}=$ 4.57). Regarding education, $21.3 \%$ reported attendance at community college, $47.2 \%$ held bachelor's degrees, and $31.6 \%$ had postgraduate qualifications. Participants were employed in the following types of organization: manufacturing $(11.0 \%)$, service $(58.1 \%)$, retail/wholesale $(5.7 \%)$, and other $(25.2 \%)$. Their responsibilities included the following: sales $(11.3 \%)$, administrative staff $(43.2 \%)$, engineering $(8.0 \%)$, research and development (R\&D) (3.7\%), production (7.6\%), and other (26.2\%). They occupied the following organizational positions: staff (28.2\%), supervisor/team leader (28.9\%), junior manager $(9.3 \%)$, middle-to-senior manager $(27.2 \%)$, and executive officer $(6.5 \%)$. The organizations for which participants worked employed the following numbers of workers: 99 or fewer (29.2\%), 100-499 (20.9\%), 500-999 (14.0\%), 1,000-4,999 (14.6\%), 5,000$9,999(10.0 \%)$, and 10,000 and more $(11.3 \%)$.

\section{Measures}

Reflection was assessed with the following seven items derived from West (1996) and Peltier et al. (2005) that described how participants reviewed and reflected on their work processes. A five-point scale was used, ranging from strongly disagree (1) to strongly agree (5).

Critical reflection was assessed with seven items derived from Peltier et al. (2005) and Kember et al. (2000). As both scales were developed for learning in higher education, the items were revised for learning in the workplace. The items used a five-point scale ranging from strongly disagree (1) to strongly agree (5).

Unlearning was measured with an eight-item scale based on the team unlearning scale developed by Akgün et al. (2006). Respondents were asked to rate how much they had changed their beliefs (beliefs in technological improvements, external environment, and customer demand) and work routines (work methods or procedures, methods for gathering and sharing information, work plans, work tools, and decision-making processes or methods) during the past year by abandoning obsolete, outdated beliefs, or routines. The items were ranked using a five-point scale ranging from hardly changed (1) to greatly changed (5). 
Work engagement was assessed using the nine-item scale developed by Schaufeli et al. (2006). The items used a five-point scale ranging from never (1) to always (5).

Social desirability was assessed with the five items derived from Paulhus (1991) regarding the prevention of potential common method bias. This was included in the model as a control variable to reduce the tendency to respond in a socially desirable manner (Podsakoff et al., 2003). The items used a five-point scale ranging from strongly disagree (1) to strongly agree (5). The average scores of the items were used in the analyses.

Control variables were included gender $(1=$ male, $2=$ female $)$, organizational position $(1=$ staff, $2=$ supervisor/team leader, $3=$ junior manager, $4=$ middle-to-senior manager, $5=$ executive officer $)$, and age $(1=20-29$ years old, $2=30-39$ years old, $3=$ $40-49$ years old, and $4=50$ years or older).

Table 1. Confirmatory factor analysis (CFA) results of measurement models.

\begin{tabular}{ccccccc}
\hline Models & $\chi^{2}$ & $d f$ & $\chi^{2} / d f$ & CFI & TLI & RMSEA \\
\hline 4-factor model & 632.05 & 428 & 1.48 & .96 & .96 & .04 \\
3-factor model & 872.00 & 431 & 2.02 & .92 & .78 & .76 \\
2-factor model & 1653.40 & 433 & 3.82 & .66 & .64 \\
1-factor model & 2294.42 & 434 & 5.29 & .10 & .12 \\
\hline
\end{tabular}

Note: $\mathrm{N}=301$. 4-factor model: each variable was loaded on a single factor; 3-factor model: reflection and critical reflection were loaded on one factor; 2-factor model: reflection, critical reflection, and unlearning were loaded on one factor; and 1-factor: all variables were loaded on a single factor.

\section{Validation of measures}

Cronbach's $\alpha$ values were calculated to assess internal consistency. The $\alpha$ values for reflection, critical reflection, unlearning, work engagement, and social desirability were $0.89,0.86,0.94,0.91$, and 0.73 , respectively. Thus, all the scores met the cut-off value of 0.70 (Nunnally, 1978).

To assess the convergent validity, a confirmatory factor analysis was conducted with four latent constructs (reflection, critical reflection, unlearning, and work engagement) and a total of 34 items. The fit indices were: $\chi^{2}=632.05(d f=428, \mathrm{p}<0.001), \chi^{2} / d f=$ $1.48, \mathrm{CFI}=0.96, \mathrm{TLI}=0.96$, and RMSEA $=0.04$. Considering the cut-off value proposed in prior research $\left(\chi^{2} / d f<2.0 ; \mathrm{CFI}>0.90\right.$; TLI $>0.90$; and RMSEA $\left.<0.06\right)(\mathrm{Hu}$ and Bentler, 1999; Lance et al., 2006), the statistics were acceptable.

\section{Evaluation of common method variance}

Common method variance was checked by the following methods. First, Harman's onefactor method was adopted. When a principal component factor analysis was performed 
with items for all variables, the first factor accounted for $32.6 \%$ of the variance. Second, a partial correlation procedure was performed, following Lindell and Whitney (2001). The effect of a theoretically unrelated marker variable, an item ("I have a lot in common with the people around me") was partialed out from the relationships between reflection, critical reflection, unlearning, and work engagement. It was found that the partial correlation matrix was equivalent to the original correlation matrix. Third, as shown in Table 1, the fit indices of the four-factor model were better than those of the single-, two-, and three-factor models. These results suggest that the effect of a common method bias was minimal in the present research. Finally, social desirability, or the tendency of individuals to present themselves in a favorable light, was included in the equation as a control variable to partial out its effects on the results because it has the potential to bias respondents' answers and mask true relationships between the variables (Podsakoff et al., 2003).

\section{Results}

Table 2 shows the descriptive statistics and correlations among variables. Several analyses were performed to examine the proposed model and hypotheses. First, to validate the hypothesized model, three models (direct-effects, partial-mediation, and fullmediation models) were analyzed using structural-equation modeling. The direct-effects model consisted of direct paths from the three variables (reflection, critical reflection, and unlearning) to work engagement, whereas the partial-mediation model involved both direct and indirect paths from reflection and critical reflection to work engagement (Figure 1). The full-mediation model excluded two paths (reflection $\rightarrow$ work engagement and critical reflection $\rightarrow$ work engagement) from the partial-mediation model. The fit indices of the three structural models, shown in Table 3, indicate that the fit index for the partial-mediation model was better than other two models. The indices for the partialmediation model indicate good adaptability $\left(\chi^{2}=762.29, d f=536, \chi^{2} / d f=1.42, \mathrm{CFI}=\right.$ 0.96 , TLI $=0.96$, RMSEA $=0.04)$, considering the cut-off criteria $(\mathrm{Hu} \&$ Bentler, 1999; Lane et al., 2006). These results suggest that the proposed model was valid. 
Table 2. Means, standard deviations, reliabilities, and correlations of the study variables $(\mathrm{n}=301)$.

\begin{tabular}{|c|c|c|c|c|c|c|c|c|c|}
\hline & $\mathrm{M}$ & SD & 1 & 2 & 3 & 4 & 5 & 6 & 7 \\
\hline 1 Gender & 1.49 & 0.50 & - & & & & & & \\
\hline 2 Age & 4.71 & 1.32 & -.06 & - & & & & & \\
\hline 3 Position & 2.54 & 1.32 & $-.21^{\cdots}$ & $.15^{\circ}$ & - & & & & \\
\hline 4 Social desirability & 3.54 & 0.67 & $-.14^{\circ}$ & -.02 & $.20^{\prime \prime}$ & $(.73)$ & & & \\
\hline 5 Reflection & 4.08 & 0.64 & -.14 & .02 & $.24^{\cdots+}$ & $.37 \cdots$ & $(.89)$ & & \\
\hline 6 Critical reflection & 3.83 & 0.65 & -.09 & .00 & $.23^{\cdots \cdots}$ & $.43^{\cdots}$ & $.63 \cdots$ & $(.86)$ & \\
\hline 7 Unlearning & 3.44 & 0.93 & -.14 & -.03 & $.27^{\cdots \cdots}$ & $.45^{\cdots}$ & $.46^{\cdots}$ & $.59^{\cdots}$ & $(.94)$ \\
\hline 8 Work engagement & 3.61 & 0.74 & -.14 & -.06 & $.29^{\cdots}$ & $.43^{\cdots}$ & $.47^{\cdots}$ & $.53^{\cdots}$ & $.58^{\cdots} \quad(.91)$ \\
\hline
\end{tabular}

Table 3. Fit indices of structural models.

\begin{tabular}{ccccccc}
\hline Models & $\chi^{2}$ & $d f$ & $\chi^{2} / d f$ & CFI & TLI & RMSEA \\
\hline Direct-effects model & 949.39 & 539 & 1.76 & 0.93 & 0.92 & 0.05 \\
Full-mediation model & 782.37 & 538 & 1.45 & 0.96 & 0.95 & 0.04 \\
Partial-mediation model & 762.29 & 536 & 1.42 & 0.96 & 0.96 & 0.04 \\
\hline
\end{tabular}

Note: The direct-effects model included direct paths from three variables to work engagement, the partial-mediation model is described in Figure 1, and the full-mediation model excluded two paths (reflection $\rightarrow$ work engagement, and critical reflection $\rightarrow$ work engagement) from the partial mediation model. 
Table 4. Results of structural equation modeling (Partial mediation model).

\begin{tabular}{|c|c|c|c|c|}
\hline \multicolumn{3}{|c|}{ Structural path } & \multirow{2}{*}{$\begin{array}{r}\text { Estimate } \\
0.63\end{array}$} & \multirow{2}{*}{$\frac{t \text {-value }}{13.39^{* * *}}$} \\
\hline Reflection & $\rightarrow$ & Critical reflection & & \\
\hline Reflection & $\rightarrow$ & Unlearning & 0.01 & 0.02 \\
\hline Critical reflection & $\rightarrow$ & Unlearning & 0.54 & $6.74^{* * *}$ \\
\hline Reflection & $\rightarrow$ & Work engagement & 0.10 & 1.31 \\
\hline Critical reflection & $\rightarrow$ & Work engagement & 0.23 & $2.39^{*}$ \\
\hline Unlearning & $\rightarrow$ & Work engagement & 0.33 & $4.86^{* * *}$ \\
\hline \multicolumn{5}{|l|}{ Control variables } \\
\hline Social desirability & $\rightarrow$ & Reflection & 0.35 & $6.53^{* * *}$ \\
\hline Social desirability & $\rightarrow$ & Critical reflection & 0.20 & $3.94^{* * *}$ \\
\hline Social desirability & $\rightarrow$ & Unlearning & 0.19 & $3.63^{* * *}$ \\
\hline Social desirability & $\rightarrow$ & Work engagement & 0.12 & $2.28^{*}$ \\
\hline Gender & $\rightarrow$ & Reflection & -0.06 & -1.03 \\
\hline Gender & $\rightarrow$ & Critical reflection & 0.04 & 0.79 \\
\hline Gender & $\rightarrow$ & Unlearning & -0.04 & -0.89 \\
\hline Gender & $\rightarrow$ & Work engagement & -0.04 & -0.77 \\
\hline Age & $\rightarrow$ & Reflection & -0.01 & -0.14 \\
\hline Age & $\rightarrow$ & Critical reflection & -0.02 & -0.32 \\
\hline Age & $\rightarrow$ & Unlearning & -0.04 & -0.87 \\
\hline Age & $\rightarrow$ & Work engagement & -0.08 & -1.77 \\
\hline Position & $\rightarrow$ & Reflection & 0.17 & $2.95^{* *}$ \\
\hline Position & $\rightarrow$ & Critical reflection & 0.06 & 1.27 \\
\hline Position & $\rightarrow$ & Unlearning & 0.11 & $2.17^{*}$ \\
\hline Position & $\rightarrow$ & Work engagement & 0.12 & $2.39^{*}$ \\
\hline
\end{tabular}

Note: $* \mathrm{p}<.05 ; * \mathrm{p}<.01 ; * * \mathrm{p}<.001$

Table 5. Results of indirect effects based on bootstrap estimates.

\begin{tabular}{cccccccc}
\hline \multirow{2}{*}{ Indirect effects } & \multirow{2}{*}{ Estimate } & \multirow{2}{*}{$\mathrm{SE}$} & $p$ & \multicolumn{3}{c}{ Bias-corrected 95\% CI } & \multirow{2}{*}{ Hypothesis } \\
\cline { 5 - 6 } $\mathrm{R}=>\mathrm{CR}=>\mathrm{UL}$ & 0.35 & 0.08 & $* * *$ & & Lower & Upper & \\
$\mathrm{CR}=>\mathrm{UL}=>$ WE & 0.18 & 0.06 & $* *$ & 0.10 & 0.52 & $\mathrm{H} 1$ \\
$\mathrm{R}=>\mathrm{CR}=>$ WE & 0.15 & 0.07 & $*$ & 0.03 & 0.27 & $\mathrm{H} 2$ \\
\hline
\end{tabular}

Note. $\mathrm{N}=301$. Standardized estimates are reported. Bootstrap sample size $=1000 . \mathrm{R}=$ reflection; $\mathrm{CR}=$ critical reflection; $\mathrm{UL}=$ unlearning; $\mathrm{WE}=$ work engagement. ${ }^{*} \mathrm{p}<.05 ; * * \mathrm{p}<.01 ; * * \mathrm{p}<.001$. 
The results of the proposed model (partial-mediation model) are shown in Table 4 and Figure 2. Gender, age, positions, and social desirability were included as independent variables with regard to reflection, critical reflection, unlearning, and work engagement to control for their effects on the results (Table 4). The results indicate a positive relationship between reflection and critical reflection $(0.63, p<0.001)$, between critical reflection and unlearning $(0.54, \mathrm{p}<0.001)$, between critical reflection and work engagement $(0.23, p<0.05)$, and between unlearning and work engagement $(0.33, p<$ $0.001)$.

To test the hypothesized mediating relationships, the bootstrapping estimates using 1,000 random samples were performed with the $95 \%$ confidence interval (CI). Table 5 shows that the CIs for all three effects exclude zero (reflection $\rightarrow$ critical reflection $\rightarrow$ unlearning; 95\% CI [0.24, 0.52]: critical reflection $\rightarrow$ unlearning $\rightarrow$ work engagement; $95 \%$ CI $[0.10,0.29]:$ reflection $\rightarrow$ critical reflection $\rightarrow$ work engagement; 95\% CI [0.03, $0.27])$. Thus, hypotheses 1,2 , and 3 were supported.

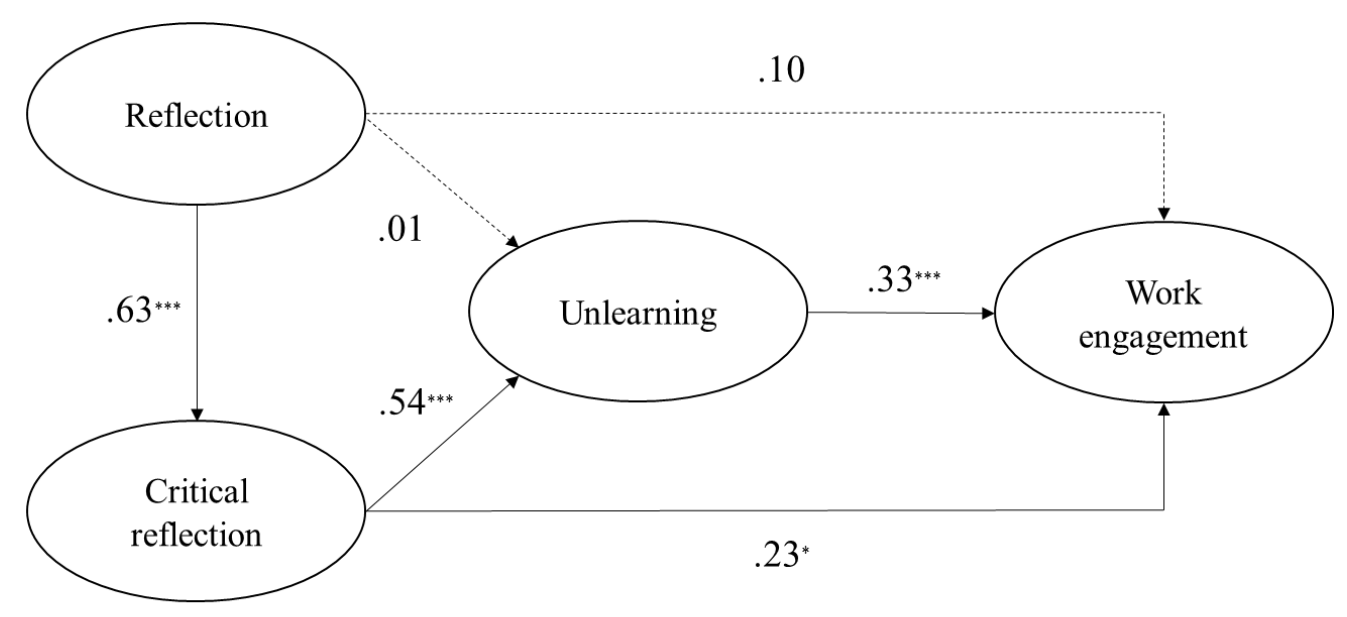

Note: $* \mathrm{p}<.05, * * * \mathrm{p}<.001$. Gender, age, positions, and social desirability were controlled in this model. The dotted line indicates no significant effect.

\section{Figure 2. Summary of results.}

\section{Discussion}

Although individual unlearning plays an important role in higher-order learning (Argyris, 1976; Metzirow, 1990, 1991, 2000), this issue has received limited attention (Hislop et al., 2014). Furthermore, scant research has quantitatively investigated the antecedents and consequences of individual unlearning. The results of this study show that critical 
reflection enhances individual unlearning, which leads to increased work engagement. The results also indicate that reflection promotes unlearning mediated through critical reflection, and that critical reflection directly influences work engagement.

\section{Theoretical implications}

This study has three theoretical implications. First, it was shown that unlearning was facilitated by critical reflection but not by reflection. These results indicate that higherorder cognitive activities, such as those used to examine taken-for-granted assumptions (Gray, 2007; Raelin, 2001), are important for unlearning beliefs and routines at work, whereas reflecting on immediate tasks or problems has no direct impact on unlearning. As suggested in prior research (Gray 2007; Raelin, 2001; Reynolds, 1998), critical reflection may enable employees to replace or select their beliefs and routines by examining taken-for-granted assumptions, thus making them more receptive to alternative ways of thinking and behaving. The results clarify the relationship between the recognition and action stages of the higher-order learning process. In addition, they suggest that a deeper level of reflection may further facilitate changes in beliefs and routines. That is, such an enhancement of the relationship between recognition and action states can minimize the knowing-doing gap (Pfeffer and Sutton, 1999). Although the role of critical reflection in enhancing individual unlearning has been discussed conceptually and studied qualitatively in the transformative learning literature (e.g., Durant et al., 2016; Mezirow, 1990, 1991; Sherlock and Nathan, 2008), this study contributes to the existing research by quantitatively confirming the insufficiently proven relationship.

Second, unlearning was found to promote work engagement. Considering that work engagement is a good predictor of important employee outcomes (Bakker and Albrecht, 2018), the findings suggest that unlearning plays a critical role in increasing employees' well-being and performance. Although work engagement has been shown to be enhanced by job crafting (Bakker et al., 2012; Demerouti et al., 2015), it does not explicitly involve questioning assumptions. The results of this study highlight the importance of abandoning obsolete beliefs and routines so that employees can be effectively engaged in their work. Although unlearning involves emotional challenges, stress, and anxiety (Visser, 2017), intrinsic motivation, which is stimulated by unlearning, may overcome such negative psychological states. This paper extends the literature by investigating the consequences of individual unlearning, which has received less attention.

Third, critical reflection had a direct influence on work engagement, suggesting that employees can be engaged with their work without changing their beliefs or routines. This may be because employees' positive, fulfilling, work-related states of mind 
(Schaufeli et al., 2002) are inspired by cognitive activity at a deeper level, including critiquing and raising questions regarding the validity of their assumptions (Mezirow, 1991). As work engagement constitutes a mode of intrinsic motivation (Demerouti et al., 2015; Reis et al., 2016), critical reflection may stimulate employees to be more deeply absorbed in their work. Although self-reflection has been proven to promote individuals' well-being, cognitive flexibility, and positive self-evaluation (Sauter et al., 2010; Simsek, 2013; Stein and Grant, 2014), this paper may be the first to report that deeper levels of reflection directly enhance work-related well-being.

Finally, the findings indicate that reflection has an impact on unlearning and work engagement through critical reflection. Although prior research has tended to stress the role of critical reflection in enhancing employee learning and performance (e.g., Cunliffe, 2004; Gray, 2007; Mezirow, 1991, 1997), general reflection is actually a preparatory step for further critical reflection that promotes unlearning and work engagement. The results are consistent with the psychological research that suggests that self-reflection enhances cognitive flexibility (Sauter et al., 2010). It is possible that individuals tend to be aware of their taken-for-granted assumptions when they reflect on their methods or approaches in their daily work environment. The present research contributes to the existing literature by showing the close linkage between reflection and critical reflection.

\section{Practical implications}

The present research has some practical implications. First, to help employees engage in their work, organizations need to help them to abandon obsolete or outdated beliefs and work routines. It may then be effective to provide them with opportunities, such as training programs or workshops, to reflect critically on their work approaches, to identify which beliefs or routines must be given up. 'After-event reviews' may be useful for employees to reflect on their practices in the workplace (DeRue et al., 2012). In terms of the importance of managers' ambidextrous behavior, balancing exploitation and exploration (Mom et al., 2007, 2015), participants should be encouraged both to improve their work processes through general reflection and to unlearn beliefs and routines through critical reflection.

Second, it may be difficult for ordinary employees to perform critical reflection, because it requires them to reassess taken-for-granted assumptions, which is implicit knowledge. Indeed, managers may not be aware of the fact that general reflection tends to promote critical reflection. Specifically, when employees are engaged in periodical reflection of their work processes, they will have opportunities to reflect critically on the frameworks or assumptions within their approaches. Thus, organizations should 
encourage managers to develop practices to facilitate periodic reflection on work during regular meetings or interviews. Such communication practices can be a basis for critical reflection in the workplace.

Finally, formal training programs should also be developed to enhance skills for appropriate reflection and unlearning. In particular, because critical reflection is closely linked to unlearning, such programs should emphasize the connection. Specifically, in such programs, participants should learn how to reflect on the deeper levels of their beliefs and knowledge as well as how to identify obsolete and outdated ones that should be relinquished. As mentioned above, it is also necessary to train participants to balance exploration through unlearning and exploitation in terms of organizational ambidexterity (Lavie et al., 2010; Raisch et al., 2009).

\section{Limitations and future research}

This study has several limitations. First, the scale for assessing individual unlearning was developed on the basis of the team unlearning scale, created by Akgün et al. (2006), which conceptualized unlearning as changes in beliefs and routines. This is because a measurement scale for individual unlearning has not been reported in the literature. Thus, further research should test the scale's validity and reliability in various contexts.

Second, critical reflection was measured based on items derived from research in higher education (Kember et al., 2000; Peltier et al., 2005). As the scale of critical reflection was validated using CFA and Cronbach's $\alpha$ and was highly correlated with reflection, which has been studied in work contexts, there are no major problems with the scale. However, further work is necessary to validate the applicability of the scale to organizational or work contexts.

Third, this study did not distinguish between wiping and deep unlearning (Hislop et al., 2014). However, the unlearning measured here may include deep unlearning given the strong positive relationship between unlearning and critical reflection, which involves reviewing taken-for-granted assumptions or values. Future research should distinguish the level of unlearning and develop measurement scales that are able to identify lowerlevel unlearning, such as wiping, and higher-level ones, such as deep unlearning.

Fourth, it is possible that external or situational factors affect critical reflection and unlearning. For example, Akgün et al. (2006) reported that environmental turbulence had both direct and indirect impacts, which were mediated through team crisis and anxiety, on team unlearning. Thus, it is important to examine the effect of situational factors, such as leadership or performance feedback (Greve, 1998; Silverman et al., 2005), on individual unlearning. 
Fifth, industry, job characteristics, organizational culture, and national culture may also influence unlearning processes. Considering the findings that knowledge-related processes and critical thinking skills differ between Western and Eastern cultures (Chia, 2003; Lun et al., 2010), it would be interesting to carry out comparative research among various cultures, industries, and occupations.

Finally, the survey data in the present research were collected with a cross-sectional design. Although multiple methods were performed to check for common method bias, and no serious problem was detected, a longitudinal survey should be conducted to replicate the results. It is desirable to measure variables at multiple points in time to validate the causal relationships presented in future research. In particular, in terms of the importance of ambidexterity (Mom et al., 2007, 2015), it would be interesting to use a longitudinal design to investigate how general reflection leads to critical reflection.

\section{Funding}

This work was supported by JSPS KAKENHI (grant number 26285078).

\section{References}

Agarwal UA (2014) Linking justice, trust and innovative work behaviour to work engagement. Personnel Review 4(1): 41-73.

Ahn T, Ryu S and Han I (2007) The impact of web quality and playfulness on user acceptance of online retailing. Information \& Management 44: 263-275.

Akgün AE, Lynn GS and Byrne JC (2006) Antecedents and consequences of unlearning in new product development teams. Journal of Product Innovation Management 23: 73-88.

Argyris C (1976) Single-poop and double-loop models in research on decision making. Administrative Science Quarterly 21(3): 363-375.

Argyris C (2003) A life full of learning. Organization Studies, 24(7): 1178-1192.

Ajzen I (1985) From intentions to actions: A theory of planned behavior. Action Control (pp. 11-39). Berlin: Springer.

Bakker AB and Albrecht S (2018) Work engagement: Current trends. Career Development International 23(1): 4-11.

Bakker AB and Demerouti E (2008) Towards a model of work engagement. Career Development International 13(3): 209-223.

Bakker AB, Tims M and Derks D (2012) Proactive personality and job performance: The role of job crafting and work engagement. Human Relations 65(10): 1359-1378.

Becker K (2005) Individual and organizational unlearning: Directions for future research. 
International Journal of Organizational Behaviour 9(7): 659-670.

Boud D, Cressery P and Docherty P (2006) Setting the scene for productive reflection. In: Boud D, Cressery P and Docherty P (eds.) Productive reflection at work: Learning for changing organizations (pp. 3-10). Oxon: Routledge.

Brock SE (2012) Measuring the importance of precursor steps to transformative learning. Adult Education Quarterly 60(2): 122-142.

Carson L and Fisher K (2006) Raising the bar on criticality: Students' critical reflection in an internship program. Journal of Management Education,30(5): 700-723.

Cegarra-Navarro J and Sánchez-Polo MT (2011) Influence of the open-mindedness culture on organizational memory: an empirical investigation of Spanish SMEs. International Journal of Human Resource Management 22(1):1-18.

Chia R (2003) From knowledge-creation to the perfecting of action: Tao, basho and pure experience as the ultimate ground of knowing. Human Relations 56(8): 953-981.

Christian MS, Garza AS and Slaughter JE (2011) Work engagement: A quantitative review and test of its relations with task and contextual performance. Personnel Psychology 64(1): 89-136.

Cope J (2003) Entrepreneurial learning and critical reflection: Discontinuous events as triggers for 'higher-level' learning. Management Learning 34(4):429-450.

Cotter R.J and Cullen JG (2012) Reflexive management learning: An integrative review and a conceptual typology. Human Resources Development Review 11(2): 227-253.

Cunliffe AL. (2004) On becoming a critically reflexive practitioner. Journal of Management Education 28: 407-426.

Cunliffe AL (2009) The philosopher leader: On relationalism, ethics and reflexivity-A critical perspective to teaching leadership. Management Learning 40: 87-101.

Cunliffe AL (2016) Republication of "On becoming a critically reflexive practitioner. Journal of Management Education 40(6): 747-768.

Cunliffe AL and Jun JS (2005) The need for reflexivity in public administration. Administration \& Society 37(2): 225-242.

Demerouti E, Bakker AB and Gevers JMP (2015) Job crafting and extra-role behavior: The role of work engagement and flourishing. Journal of Vocational Behavior 91: 87-96.

De Clercq D, Bouckenooghe D, Raja U and Matsyborska G (2014) Servant leadership and work engagement: The contingency effects of leader-follower social capital. Human Resource Development Quarterly 25(2): 183-212.

DeRue DS, Nahrgang JD, Hollenbeck JR and Workman K (2012) A quasi-experimental study of after-event reviews and leadership development. Journal of Applied 
Psychology 97(5): 997-1015.

Dewey J (1933) How we think: A restatement of the relation of reflective thinking to the educative process. Lexington, MA: D. C. Heath.

Durant RA, Carlon DM and Downs A (2016) The efficiency challenge: Creating a trasnformative learning experience in a principles of management course. Journal of Management Education 41(6): 852-872.

Fernandez V, Sallan JM Simo P and Enache M (2012) Organizational forgetting/unlearning: The dark side of the absorptive capacity. In: Hou H. (ed.) New Research on Knowledge Management Applications and Lessons Learned (pp. 155170). Croatia: In Tech,

Gallagher SJ, Rocco TS and Landorf H (2007) A phenomenologial study of spirituality and learning processes at work: Exploring the holistic theory of knowledge and learning. Human Resource Development Quarterly 18(4): 457-480.

Garrick A. Mak A, Cathcart S, Winwood PC, Bakker AB and Lushington K (2014) Psychosocial safety climate moderating the effects of daily job demands and recovery on fatigue and work engagement. Journal of Occupational and Organizational Psychology 87(4): 694-714.

Gray DE (2007) Facilitating management learning developing critical reflection through reflective tools. Management Learning 38(5): 495-517.

Greve HR (1998) Performance, aspirations, and risky organizational change. Administrative Science Quarterly 43: 58-86.

Hislop D, Bosley S, Coombs CR and Holland J (2014) The process of individual unlearning: A neglected topic in an under-researched field. Management Learning 45(5): 540-560.

Holland PJ, Allen BC and Cooper BK (2013) Reducing burnout in Australian nurses: The role of employee direct voice and managerial responsiveness. International Journal of Human Resource Management 24(16): 3146-3162.

Hu L and Bentler PM (1999) Cutoff criteria for fit indexes in covariance structure analysis: Conventional criteria versus new alternatives. Structural Equation Modeling 6(1): 1-55.

Jiang Z (2016) The relationship between career adaptability and job content plateau: The mediating roles of fit perceptions. Journal of Vocational Behavior 95-96: 1-10.

Kember D, Leung DYP, Jones A, Loke AY, McKay J, Sinclair K, Tse H, Webb C, Wong FKY, Wong M and Yeung E (2000) Development of a questionnaire to measure the level of reflective thinking. Assessment \& Evaluation in Higher Education 25(4): 381-395. 
Kolb DA (1984) Experiential learning: Experience as the source of learning and development. Englewood Cliffs, NJ: Prentice Hall.

Kurnam J (2006) Self-enhancement, self-regulation and self-improvement following failures. British Journal of Social Psychology, 45: 339-356.

Lane CE, Butts MM and Michels LM (2006) The sources of four commonly reported cutoff criteria: What did they really say? Organizational Research Methods 9(2): 202-220.

Lavie D, Stettner U and Tushman ML (2010) Exploration and exploitation within and across organizations. Academy of Management Annals 4(1): 109-155.

Leal-Rodríguez AL, Eldridge S, Roldán JL, Leal-Millán AG and Ortega-Gutiérrez J (2015) Organizational unlearning, innovation outcomes, and performance: The moderating effect of firm size. Journal of Business Research 68: 803-809

Lindell MK and Whitney DJ (2001) Accounting for common method variance in crosssectional research designs. Journal of Applied Psychology 86(1): 114-121.

Lu C, Wang H, Lu J, Du D and Bakker AB (2014) Does work engagement increase person-job fit? The role of job crafting and job insecurity. Journal of Vocational Behavior 84: 142-152.

Lun VM, Fischer R and Ward C (2010) Exploring cultural differences in critical thinking: Is it about my thinking style or the language I speak? Learning and Individual Differences 20: 604-616.

March JG (1991) Exploration and exploitation in organizational learning. Organization Science 2: 71-87.

Marsick VJ (1988) Learning in the workplace: The case for reflectivity and critical reflectivity. Adult Education Quarterly 38(4): 187-198.

Messmann G and Mulder RH (2015) Reflection as a facilitator of teachers' innovative work behavior. International Journal of Training and Development 19(2): 125-137.

Mezirow J (1990) How critical reflection triggers transformative learning. In: Mezirow J and Associates (eds.) Fostering critical reflection in adulthood: A guide to transformative and emancipatory learning (pp. 1-20). San Francisco: Jossey-Bass.

Mezirow J (1991) Transformative dimensions of adult learning. San Francisco: JosseyBass.

Mezirow J (1997) Transformative learning: Theory to practice. New Directions for Adult and Continuing Education 74: 5-12.

Mezirow J (2000) Learning to think like an adult: Core concepts of transformation theory. In: Mezirow $\mathrm{J}$ et al. (eds.) Learning as transformation: Critical perspectives on a theory in progress (pp. 3-33). San Francisco: Jossey-Bass. 
Mezirwo J (2003) Transformative learning as discourse. Journal of Transformative Education 1(1): 58-63.

Mom TJM, van den Bosch FAJ and Volberda HW (2007) Investigating managers' exploration and exploitation activities: The influence of top-down, bottom-up, and horizontal knowledge inflows. Journal of Management Studies 44(6): 910-931.

Mom, TJ, Fourne, SPL and Jansen JJP (2015) Managers' work experience, ambidexterity, and performance: The contingency role of the work context. Human Resource Management, 54(S1): S133-S153.

Montano DE and Kasprzyk D (2015) Theory of reasoned action, theory of planned behavior, and the integrated behavioral model. In: Glanz $\mathrm{K}$ et al. (eds.) Health Behavior and Health Education: Theory, Research and Practice (pp. 95-124). San Francisco: Jossey-Bass.

Nunnally JC (1978) Psychometric theory. 2nd edn. New York: McGraw-Hill.

Osgood DW, Wilson JK, O'Malley PM, Bachman JG and Johnston LD (1996) Routine activities and individual deviant behavior. American Sociological Review 61(4): 635655.

Paulhus DL (1991) Measurement and control of response bias. In Robinson J, Shaver P and Wrightsman LS (eds.). Measures of personality and social psychological attitudes (pp. 17-59). New York: Academic Press.

Parry ME, Kawakami T and Kishiya K (2012) The effect of personal and virtual wordof-mouth on technology acceptance. Journal of Product Innovation Management 29(6): 952-966.

Peltier JW, Hay A and Drago W (2005) The reflective learning continuum: Reflecting on reflection. Journal of Marketing Education 27(3): 250-263.

Podsakoff PM, MacKenzie SB, Lee J and Podsakoff NP (2003) Common method biases in behavioral research: A critical review of the literature and recommended remedies. Journal of Applied Psychology 88(5): 879-903.

Raelin JA (2002) “I don't have time to think!" versus the art of reflective practice. Reflection 4(1): 66-79.

Raisch S, Birkinshaw J, Probst G and Tushman ML (2009) Organizational ambidexterity: Balancing exploitation and exploration for sustained performance. Organizational Science 20(4): 685-695.

Reis D, Arndt C, Lischetzke T and Hoppe A (2016) State work engagement and state affect: Similar yet distinct concepts. Journal of Vocational Behavior 93: 1-10.

Reynolds M (1998) Reflection and critical reflection in management learning. Management Learning 29(2): 183-200. 
Rushmer R and Davies HTO (2004) Unlearning in health care. Quality \& Safety in Health Care 13: 10-15.

Russell D, Peplau LA and Cutrona CE (1980) The revised UCLA loneliness scale: Concurrent and discriminant validity evidence. Journal of Personality and Social Psychology 39(3): 472-480.

Sauter FM, Heyne D and Blote AW (2010) Assessing therapy-relevant cognitive capacities in young people: Development and psychometric evaluation of the selfreflection and insight scale for youth. Behavioural and Cognitive Psychotherapy 38: 303-317.

Schaufeli WB, Bakker AB and Salanova M (2006) The measurement of work engagement with a short questionnaire. Educational and Psychological Measurement 66(4): 701716.

Schaufeli WB, Salanova M, Gonzalez-Roma V and Bakker AB (2002) The measurement of engagement and burnout: A two sample confirmatory factor analytic approach. Journal of Happiness Studies 3: 71-92.

Shantz A, Alfes K and Latham GP (2016) The buffering effect of perceived organizational support on the relationship between work engagement and behavioral outcomes. Human Resource Management 55(1): 25-38.

Sherlock JJ and Nathan ML (2008) How power dynamics impact the content and process of nonprofit CEO learning. Management Learning 39(3): 245-269.

Silverman SB, Pogson CE and Cober AB (2005) When employees at work don't get it: A model for enhancing individual employee change in response to performance feedback. Academy of Management Executive 19(2): 135-147.

Simsek OF (2013) The relationship between language use and depression: Illuminating the importance of self-reflection, self-rumination, and the need for absolute truth. Journal of General Psychology 140(1): 29-44.

Stein D and Grant AM (2014) Disentangling the relationships among self-reflection, insight, and subjective well-being: The role of dysfunctional attitudes and core selfevaluations. Journal of Psychology 148(5): 505-522.

Tims M, Bakker AB and Xanthopoulou D (2011) Do transformational leaders enhance their follower' daily work engagement? Leadership Quarterly 22: 121-131.

Tims M, Bakker AB and Derks D (2012) Development and validation of the job crafting scale. Journal of Vocational Behavior 80(1): 173-186.

Tsang EWK (2008) Transferring knowledge to acquisition joint ventures: An organizational unlearning perspective. Management Learning 39: 5-20.

Tsang EWK and Zahra SA (2008) Organizational unlearning. Human Relations 61(10): 
1435-1462.

Van De Voorde K, Van Veldhoven M and Veld M (2016) Connecting empowermentfocused HRM and labour productivity to work engagement: The mediating role of job demands and resources. Human Resource Management Journal 26(2): 192-210.

Visser M (2017) Learning and unlearning: A conceptual note. The Learning Organization 24(1): 49-57.

West MA (2000) Reflexivity, revolution and innovation in work teams. In: Beyerlein MM, Johnson DA and Beyerlein ST (eds.) Product development teams, Vol. 5 (pp. 1-29). Stamford, CT: JAI Press.

Zimmerman BJ (2002) Becoming a self-regulated learner: An overview. Theory into Practice, 41(2): 64-70. 